\title{
CRÓNICA DE LA JURISPRUDENCIA CONSTITUCIONAL ESPAÑOLA EN EL AÑO 2018
}

Chronicle reports of classes law in the Spanish Constitutional Court 2018

\author{
ALBERTO OEHLING DE LOS REYES' \\ Universidad Complutense de Madrid \\ a.j.oehling@ucm.es
}

Cómo citar/Citation

Oehling de los Reyes, A. (2019).

Crónica de la jurisprudencia constitucional española en el año 2018.

Anuario Iberoamericano de Justicia Constitucional, 23(2), 559-580.

doi: https://doi.org/10.18042/cepc/aijc.23.19

\section{SUMARIO}

I. INTRODUCCIÓN. II. ALGUNAS CIFRAS. III. ANÁLISIS DE LA JURISPRUDENCIA: 1. Jurisdicción constitucional. Derecho procesal constitucional. 2. Fuentes del derecho. 3. Estructura territorial del Estado. 4. Organización de los poderes públicos. 5. Derechos fundamentales. Biblografía.

\section{INTRODUCCIÓN}

Nuevamente particularmente importante e interesante ha sido este año para la vigencia de la Constitución española de 1978 y para el Tribunal Cons-

1 Profesor contratado doctor de Derecho Constitucional de la Universidad de las Islas Baleares (en excedencia). 
titucional. En primer lugar, porque en 2018 se cumplían cuarenta años de la Constitución, lo que ha llevado a la realización por el Tribunal de distintos actos de celebración académicos e institucionales; según la Memoria de 2018 (Tribunal Constitucional, 2018), hasta 170 visitas de colegios, institutos y de grupos de alumnos de universidades se han llegado a realizar en la sede de Doménico Scarlatti por este motivo y por las distintas jornadas de puertas abiertas de la institución, lo cual nos parece una excelente iniciativa de cara a la información al ciudadano de la insustituible función que realiza el Tribunal Constitucional como protector de la Constitución y los derechos y libertades fundamentales. En segundo lugar, porque este año el Tribunal y su labor también han recibido un importante reconocimiento por parte de otras instituciones. Ya el año pasado el Informe de evaluación de los órganos constitucionales y reguladores, elaborado por el Consejo de Transparencia y Buen Gobierno, dio una puntuación de 9,83 al Tribunal en materia de cumplimiento de la Ley 19/2013, de 9 de diciembre, de Transparencia, Acceso a la Información Pública y Buen Gobierno, obteniendo también un primer puesto en comparación con otras entidades públicas, lo cual es bastante significativo (Consejo de Transparencia y Buen Gobierno, 2017). En 2018, en abril, el Tribunal recibió un homenaje del Colegio de Registradores de la Propiedad y Mercantiles de España a través de la publicación del libro Un Tribunal para la Constitución (Beltrán de Felipe y Sarmiento Ramírez-Escudero, 2017), un libro absolutamente innovador y fundamental sobre la historia del Tribunal que integra incluso el texto de diversas entrevistas a algunos magistrados eméritos y otros protagonistas del Tribunal Constitucional (Requejo Pagés, 2018). Y, en tercer lugar, en fin, porque en 2018 el Tribunal ha dictado también importantes resoluciones derivadas de la situación política en Cataluña, no solo doctrina muy notable de referencia en materia de determinación de las bases del Estado autonómico y del principio de lealtad constitucional (art. 2 de la CE y STC 247/2007, de 12 de diciembre), sino también testimonio nuevamente de las debilidades del Estado y la Constitución frente a los extremismos más hórridos y contrarios a los mínimos de convivencia y paz social (art. 10.1 CE), que hacen un uso espurio e interesado de las propias garantías constitucionales y de las instituciones con fines partidistas y de reversión del sistema constitucional y del orden basado en la dignidad de la persona y los derechos fundamentales ${ }^{2}$. En esta jurisprudencia —a las SSTC 10/2018, de 5 de febrero, 27/2018, de 5 de marzo, y 47/2018, de 26 de abril, entre otras, nos remitimos - late el esfuerzo del Tribunal por restituir la normalidad constitucional, como también la repetida necesidad de apelación a los principios más elementales de la civilización jurídica occidental de supremacía constitucional, Estado de derecho e igualdad

2 Véase también, por ejemplo, De Miguel Bárcena (2018). 
del ciudadano, como conceptos base de fundamentación de las resoluciones judiciales y contra los cuales se posicionan de plano estos partidos nacionalistas.

Dada la limitación de espacio de la que disponemos, este trabajo solamente consiste en una cita y comentario muy breve de determinados casos seleccionados del Tribunal Constitucional en 2018, para una relación completa puede el lector dirigirse —aparte de la relación de resoluciones y notas que el Tribunal Constitucional ofrece en su web-, especialmente, como en las crónicas de años anteriores, a la estadística y Memoria del Tribunal Constitucional del año 2018, los estudios de resoluciones realizados por el Área de Derecho Constitucional de la Universidad Carlos III (Elvira Perales, Espinosa Díaz Pajares Montolío, Fraile Ortiz, Gómez Lugo y Baamonde Gómez) (Elvira Perales et al., 2018a; 2018b; 2019) y los estudios cuatrimestrales realizados por Duque Villanueva, Ortega Carballo, Losada González y De la Quadra-Salcedo Janini para la Revista Española de Derecho Constitucional (Duque Villanueva et al., 2018a; 2018b; 2019). Este comentario parte de dichos trabajos, como también de la Gaceta de Jurisprudencia Constitucional (enero-marzo, abril-junio, julio-septiembre y octubre-diciembre de 2018, respectivamente) ${ }^{3}$; luego, igualmente, como se irá citando, se ha consultado algún otro análisis doctrinal que ha tratado de forma específica alguna de las decisiones del Tribunal Constitucional del año 2018.

\section{ALGUNAS CIFRAS}

Según la Memoria de 2018, el año pasado ingresaron en el Tribunal Constitucional un total de 6977 recursos, que se reparten de la siguiente manera: 12 recursos de inconstitucionalidad, 39 cuestiones de inconstitucionalidad, 3 autocuestiones del art. 55.2 de la LOTC, 6918 recursos de amparo (32 avocados al Pleno), 3 impugnaciones de disposiciones de las comunidades autónomas y 2 cuestiones prejudiciales de validez de normativa fiscal foral. El número de casos que han entrado en sede constitucional se ha incrementado significativamente respecto a 2017 en un total de 596 asuntos (6381 en 2017). La causa de este incremento se debe a la mayor interposición de recursos de amparo. Así, por tanto, se rompe la tendencia descendente que hemos ido comentando en años anteriores en relación con la cadencia de interposición de demandas de amparo; por ejemplo, si en el año 2015 hubo 7203 demandas de amparo, en 2016 hubo un total de 6685 y en 2017 se presentaron 6286, ahora, en cambio, la cifra sube hasta 6918.

3 Disponible en red en https://bit.ly/2pBgN3f. 
En lo que se refiere en particular a las demandas de amparo, la estadística de 2018 del Tribunal Constitucional pone de manifiesto que la gran mayoría siguen siendo recursos relativos al derecho a la tutela judicial efectiva del art. $24 \mathrm{CE}$, que suma un total de 4872 demandas, es decir, casi un 70,4\% del total, siguiéndole bastante de lejos el derecho a la igualdad y no discriminación del art. $14 \mathrm{CE}$, con un número de 1008; luego ya le siguen el derecho a la legalidad penal del art. $25 \mathrm{CE}$, con una cifra de 892 recursos, y el derecho a la libertad personal del art. $17 \mathrm{CE}$, con 490. Interesa reseñar que, además, se presentaron 4 recursos de amparo electorales y 29 frente a actos parlamentarios sin fuerza de ley del art. 42 LOTC. De estos 6918 recursos, solamente se admitieron a trámite 115 . El principal motivo de inadmisión han sido las típicas deficiencias en orden a la justificación del requisito de especial transcendencia constitucional del recurso del art. 49.1 de la LOTC, que - entre falta del mismo, deficiente explicación o, directamente, por falta evidente de trascendencia - suman un total de 4454 inadmisiones en vía de amparo; luego, la siguiente causa de inadmisión más frecuente fue la falta de agotamiento de la vía judicial previa, con un total de 607 inadmisiones.

Hay que indicar, por otra parte, que, a finales de 2018, todavía se hallaban admitidos a trámite, pero pendientes de resolución por parte del Pleno, un total de 36 recursos de inconstitucionalidad, 11 cuestiones de inconstitucionalidad, bien a resolver en Pleno o salas, 2 conflictos positivos de competencia, 1 cuestión prejudicial sobre normas forales fiscales, 2 impugnaciones de disposiciones autonómicas y, además, 41 recursos de amparo avocados; luego, por parte de las salas, 98 recursos de amparo y 4 cuestiones de constitucionalidad. Pendientes de decisión sobre su admisión por el Pleno había 1 recurso de inconstitucionalidad y 4 cuestiones de inconstitucionalidad; por parte de las salas, 3180 recursos de amparo (1755 correspondientes a la Sala Primera y 1425 de la Sala Segunda).

\section{ANÁLISIS DE LA JURISPRUDENCIA}

\section{JURISDICCIÓN CONSTITUCIONAL. DERECHO PROCESAL CONSTITUCIONAL}

El art. 149.1 del Reglamento de Cataluña en su versión vigente determina, en relación con la investidura del presidente de la Generalidad de Cataluña, expresamente, que «el candidato presenta, sin límite de tiempo, el programa de gobierno y solicita la confianza del Pleno». Se entiende de forma inequívoca - por el uso del presente de indicativo- que dicha exposición es de forma presencial. El mismo texto no prevé para este acto ningún tipo de 
delegación ni otro tipo de excepción de cara a la presentación del candidato y su programa en la Cámara. En cambio, por vía de las resoluciones del presidente del Parlamento de Cataluña de 23 de enero de 2018 y de 25 de enero de 2018, se procedía a la convocatoria de sesión plenaria para permitir la presentación de candidatura en ausencia. Se hablaba de que se podía investir al candidato por vía telemática, incluso en forma de holograma ${ }^{4}$. Podemos imaginar lo que podría suponer la aceptación de este tipo de práctica, que se haría extensiva al resto de representantes de la Asamblea, pudiendo asistir a los plenos por vía digital, desde casa. Ante esta nueva ocurrencia del Parlamento catalán, el Gobierno central interpuso recurso de impugnación de disposición sin fuerza de ley de las comunidades autónomas del art. 161.2 de la CE, aparte solicitaba como medida cautelar la suspensión de cualquier tipo de sesión de investidura que no fuera protagonizada ad personam por el candidato. Naturalmente, el Tribunal Constitucional, en su ATC 5/2018 (Pleno), de 27 de enero, suspende cautelarmente la posibilidad de realizar la elección en ausencia del candidato. En efecto, más allá del que el Reglamento de la Cámara no prevé dicha alternativa, ni es serio un nombramiento por vía Skype, videoconferencia u otro medio telemático, no ofrece tampoco las suficientes garantías, sobre todo en una sesión de este tipo, con intervenciones sucesivas de los distintos representantes parlamentarios por períodos de treinta minutos, con réplicas y contrarréplicas (art. 149.2 del Reglamento), se pueden producir fallos de conexión, etc. En definitiva, el Tribunal entiende que cabe también, con motivo de recurso por vía de los arts. 161.2 CE y 76 y 77 de la LOTC, la solicitud de medidas cautelares excepcionales; en este caso, por los «perjuicios de imposible o difícil reparación» que puedan derivarse de un nombramiento irregular de este tipo, por lo que determina la imposibilidad de realizar "cualquier sesión de investidura que no sea presencial», como también de celebrar el debate y la votación de investidura de un diputado «como candidato a Presidente de la Generalitat a través de medios telemáticos o por sustitución por otro parlamentario». Posteriormente, por ATC 49/2018 (Pleno), de 26 de abril, se admitiría a trámite la impugnación de dichas disposiciones autonómicas. A juicio del Tribunal, cabe frente a este tipo de decisiones parlamentarias la utilización de la vía de los arts. 161.2 CE y 76 y 77 de la LOTC, por la naturaleza y efectos jurídicos de las mismas y por su especial incidencia en el proceso de proposición e investidura del presidente de la comunidad autónoma.

La STC 2/2018 (Pleno), de 11 de enero, resuelve un recurso de inconstitucionalidad interpuesto por el presidente del Gobierno, por razones com-

4 Véase la noticia en el diario $A B C$, edición impresa de 12 de enero de 2018, p. 19. 
petenciales, contra distintos preceptos de la Ley 7/2016, de 21 de julio, de medidas extraordinarias contra la exclusión social, de la comunidad autónoma de Extremadura. Interesa este fallo en particular por cuanto el letrado de la Junta de Extremadura, en sus alegaciones, entendía no se cumplía el requisito de legitimación para interponer el recurso de inconstitucionalidad de los arts. 162.1.a y 32.1 LOTC, ya que el recurso se había planteado por el abogado del Estado por orden de la vicepresidenta del Gobierno actuando en suplencia del presidente del Gobierno, el cual se encontraba en viaje oficial en Sevilla. El letrado entiende que, por razones de Estado, quepa suplencia cuando el presidente está fuera de territorio nacional, pero no así cuando este se encuentra de viaje dentro de España. El Tribunal no lo entiende así, dejando entrever que la previsión de suplencia cara a la presentación del recurso no se refiere solamente a cubrir la mera situación de lejanía.

Ni la Constitución —dice el Pleno-, que no se ocupa de la suplencia, ni el artículo 13.1 de la Ley 50/1997, de 27 de noviembre, del Gobierno, que regula la suplencia del Presidente del Gobierno en los casos de vacante, ausencia o enfermedad, ni las normas jurídicas que disciplinan la suplencia para el resto de titulares o miembros de órganos administrativos en nuestro ordenamiento jurídico (art. 13 de la Ley 40/2015, de 1 de octubre, de régimen jurídico del sector público), diferencian entre la ausencia temporal dentro y fuera de España, ni exigen que la situación de ausencia tenga una determinada duración o deba extenderse hasta la finalización del plazo en el que el titular del órgano deba ejercer la correspondiente función, facultad o potestad.

En materia de legitimación interesan también la STC 14/2018, de 20 de febrero, del Pleno. Es sabido que las comunidades autónomas pueden, de conformidad con el art. 33 de la LOTC, interponer un recurso de inconstitucionalidad contra disposiciones con rango de ley incluso cuando estas no afecten al ámbito de su autonomía 5 . En cambio, el Parlamento de Navarra intentó su personación no por vía de recurso formal sino por medio de un mero escrito de adhesión a los recursos de inconstitucionalidad presentados por otras instituciones (respectivamente, cincuenta diputados y el Gobierno de Cataluña), fuera de plazo y sin haberse constituido como parte en el proceso. El Tribunal Constitucional no admite esa vía de adhesión al proceso abierto

5 En relación con la limitación de legitimación del art. 32.2 en tanto «pueda afectar a su propio ámbito de autonomía», el Tribunal Constitucional ha ido modificando «este criterio tan profundamente que, desde el punto de vista práctico, la limitación que en él se impone a la legitimación de las Comunidades Autónomas ha desaparecido casi por entero" (Rubio Llorente, 2012). 
por otros, por la falta de manifestación previa y falta de ejercicio de acción en los términos previstos en la LOTC. En la STC 31/2018, de 10 de abril, también del pleno, ratifica esta posición diciendo que «no resulta procesalmente admisible que una institución legitimada para interponer el recurso de inconstitucionalidad (arts. 162.1 a de la CE y 32.2 de la LOTC) pretenda sustituir el cauce que para ello ha dispuesto el ordenamiento jurídico por una figura de adhesión, que significaría reabrir indebidamente el plazo preclusivo en el que tuvo la oportunidad de impugnar» la norma objeto del proceso.

$\mathrm{El}$ art. 134.6 CE reconoce la figura del veto presupuestario del Gobierno de cara a la tramitación de iniciativas legislativas que supongan aumento de los créditos o disminución de los ingresos presupuestarios. Se trata de una "potestad gubernamental prácticamente ilimitada», frente a la que los órganos de dirección de la Cámara tienen poco que hacer (Delgado Ramos, 2018a). En el caso que se suscita en la STC 34/2018, de 12 de abril (Pleno), trata sobre una situación en la que la Mesa del Congreso de los Diputados no atiende — sobre la base de que el Gobierno no justificaba «de forma objetiva y suficiente» que la norma vetada supusiera realmente un aumento de créditos o disminución de ingresos de los PGE - a la paralización, dando trámite a la misma para su discusión y aprobación. El Gobierno recurrió esta situación por vía de recurso del art. 73 de la LOTC, vía conflictos entre órganos constitucionales del Estado, por estimar que la Mesa asumía atribuciones por encima de sus facultades, solicitando su revocación. En lo que ahora interesa, el Tribunal Constitucional también evalúa el uso por el Gobierno del conflicto de atribuciones para trasladar al Tribunal el examen de licitud. A juicio del Tribunal, en efecto, un acuerdo de la Mesa de este tipo «se adecúa efectivamente al objeto propio del conflicto entre órganos constitucionales del Estado», por cuanto, de conformidad con el art. 134.6 CE, la paralización es una facultad atribuida al Ejecutivo y, por tanto, la situación suscitada, en cuanto «menoscabo de la competencia del Gobierno», puede ser impugnada por este por vía del 73 LOTC $^{6}$. También, sobre la misma cuestión, encontramos la STC 44/2018, de 26 de abril, del Pleno, que resolvía el conflicto de atribuciones interpuesto igualmente por el Ejecutivo frente a los acuerdos de la Mesa del Congreso que procedieron a la tramitación - a pesar de la interposición de veto en razón a pérdidas de ingresos presupuestarios - de una proposición de ley de un grupo parlamentario sobre la modificación del art. 42.1 del Estatuto de los Trabajadores para garantizar la igualdad en las condiciones laborales de los trabajadores subcontratados. El Tribunal Constitucional desestima el conflicto interpuesto por el Gobierno al entender que no se ha producido «el menos-

6 Sobre ello, Alonso García (2018). 
cabo de la competencia reconocida por el artículo 134.6 CE», ya que el veto ejercido no se encuentra justificado con su presupuesto habilitante, esto es, "precisar adecuadamente las concretas partidas presupuestarias del presupuesto en vigor que se verían directamente afectadas por esa iniciativa legislativa, limitándose a aportar una estimación de impacto económico, insuficiente por tanto a estos efectos» (Delgado Ramos, 2019).

En materia de insuficiencia en el juicio de aplicabilidad y relevancia en la presentación de la cuestión de inconstitucionalidad de los arts. $163 \mathrm{CE}$ y 35 LOTC, interesa citar el ATC 61/2018, de 5 de junio (Pleno). El Tribunal recuerda la obligación que pesa sobre el órgano judicial de explicar debidamente la presunción de inconstitucionalidad del precepto, siendo del todo insuficiente la exposición global y carente de una razón suficientemente desarrollada, también — como era el caso- la simple reproducción del precepto que se tacha de inconstitucional sin efectuar por sí mismo ningún análisis puntual y preciso de la grave censura de inconstitucionalidad que se alude. En el ATC 71/2018, de 20 de junio (Pleno), se deja entrever cómo el juicio de aplicabilidad y relevancia debe extenderse a todas las facetas y efectos de inconstitucionalidad del precepto impugnado.

En relación con el agotamiento de la vía judicial y el art. 241.1 LOPJ, interesa el ATC 65/2018, de 18 de junio (Sección Primera). El caso devenía de una fotografía supuestamente no consentida tomada en un quirófano de un hospital público de un sujeto gravemente herido y posteriormente hecha viral por WhatsApp, por lo que el afectado solicitó indemnización por lesión del art. 18.1 CE. Cuando llegó el caso a la justicia ordinaria, la Sala de lo Contencioso-Administrativo del Tribunal Superior de Justicia de Murcia desestimó el recurso, por entender no suficientemente acreditado el daño ni la negligencia del hospital, razón por la cual la representación procesal interpuso incidente de nulidad de actuaciones, no recurso de casación ante la Sala de lo Contencioso-Administrativo del Tribunal Supremo, de conformidad con lo previsto en el art. 86.1 de la Ley 29/1998, de 13 de julio, reguladora de la Jurisdicción Contencioso-Administrativa. La Sala de lo Contencioso-Administrativo del Tribunal Superior de Justicia inadmitió el incidente, por cuanto, de acuerdo con el art. 241.1 LOPJ, como requisito necesario para poder interponer el mismo se requiere precisamente que la resolución "no sea susceptible de recurso ordinario ni extraordinario», y aquí cabía — como se ha dicho- recurso de casación. La parte interpone así a la postre recurso de amparo por lesión del derecho a la tutela judicial, a su juicio, la casación en este caso era un puro formalismo por estar esta avocada a su inadmisión por la falta de interés casacional del asunto, en aplicación de la Ley Orgánica 7/2015, de 21 de julio (hoy art. 88 de la Ley 29/1998), que determina el «interés casacional objetivo para la formación de la juris- 
prudencia» como único criterio de admisibilidad del recurso, cerrando la puerta a recursos cuyo objetivo sea la revisión de los hechos o la valoración de la prueba. En cambio, al final el Tribunal Constitucional no le da la razón, dado que, según él, el hecho de que la parte crea a ciencia cierta que el recurso de casación no tiene ninguna posibilidad de ser admitido, dadas las cuestiones sobre las que iba a versar, no exime de su presentación ante el Tribunal Supremo, ni cabe suplantarlo a efectos de que evalúe si efectivamente la materia reviste o no interés casacional. En definitiva, el agotamiento de la vía judicial previa al recurso de amparo exige también, en su caso, haber intentado el recurso de casación ${ }^{7}$.

En relación con la falta de agotamiento de la vía judicial previa al amparo, interesan las SSTC 129, 130 y 131 /2018 (Pleno), de 12 de diciembre, resultado de una serie de recursos de amparo por supuesta lesión al derecho al juez ordinario predeterminado por la ley (art. 24.2 CE) interpuestos por algunos de los golpistas que se alzaron en octubre de 2017. En términos generales, la pretensión última de la demanda era negar la competencia del Tribunal Supremo para investigar y enjuiciar los hechos por los que eran procesados en favor del Tribunal Superior de Justicia de Cataluña, que imaginaban que hubiera sido más benévolo en su procesamiento, en contradicción total con todos los principios clásicos del Estado de derecho (igualdad ante la ley, igualdad en aplicación de ley, proceso con todas las garantías; también el mismo principio de juez ordinario predeterminado por la ley, e igual sujeción de todos los ciudadanos a los mismos jueces y tribunales). Lo cierto es que el propio Estatuto de Cataluña (art. 57.2) determina expresamente la competencia del Tribunal Supremo para casos de responsabilidad penal de los representantes de la Asamblea Legislativa de la comunidad autónoma, lo que englobaría el conocimiento de delitos tales como los de rebelión y sedición de los arts. 472 y 544 del Código Penal —delitos por los que eran procesados-, que, por buscar la destrucción de la CE y del orden fundado en la dignidad de la persona y los derechos fundamentales, tiene efecto sobre todo el territorio y no solo sobre una determinada región de España. En cualquier caso, y esto es obvio en un Estado constitucional moderno, sobre la base de los principios expuestos (igualdad ante la ley, sometimiento a los mismos jueces y tribunales, etc.), interesa que la determinación del juez competente sea determinada también sobre la base del principio de unidad jurisdiccional del art. 117.5 CE y por las reglas de la LOPJ, evitando que en este caso conozca de la causa un tribunal especial, a elección de parte, y que por motivos políticos cree también gozar de pre-

Sobre ello, Triana Reyes (2018). 
rrogativa de elección de juez. Luego, aparte, hay que decir que el recurso de amparo se planteaba prematuramente, por cuanto se presentó el recurso sin haber dado pie a la finalización del proceso matriz ante el Tribunal Supremo. De alguna forma, la parte intentaba explicar en las razones de su recurso que cabía también soslayar en su caso el requisito del art. 44.1.a LOTC, en lo relativo a la necesidad de agotamiento de la vía previa judicial, dado que la lesión de derechos fundamentales a los que aludía (derecho a la libertad, tutela judicial efectiva) se estaba realizando por el propio órgano judicial que conocía de la causa, razón por la cual entendía infructuoso agotar la vía judicial en su caso por estas supuestas lesiones producidas por dicho órgano judicial, optando por obviar los posibles recursos previos extraordinarios en vía ordinaria; también el incidente de recusación a fin de impetrar el control de la supuesta falta de imparcialidad de la Sala de la que igualmente se quejaba. Con ello, en definitiva, la parte trataba de solicitar otra dispensa por su condición política, a saber, que se le dispensara, a diferencia de cualquier otro ciudadano, de tener que agotar la vía judicial previa en su caso ante estas supuestas irregularidades del órgano judicial, y se le reconociese la prerrogativa especial de poder acudir per saltum directamente ante el Tribunal Constitucional, sin ni siquiera haber dado pie a la Sala de terminar el procedimiento. Dicho de otra forma, solicitaba otra excepción del principio de igualdad ante la ley y en aplicación de ley y del principio de sujeción de todos los ciudadanos a las mismas leyes y a los mismos tribunales del ley del art. $14 \mathrm{CE}$, eximiéndole de las exigencias en orden a la interposición del amparo constitucional del art. 44 de la LOTC. Naturalmente, el Tribunal Constitucional procede a la inadmisión de los recursos. Dice el Tribunal, recordando anterior jurisprudencia:

En lo que se refiere al proceso penal, hemos venido manteniendo una regla general a tenor de la cual, en aquellos casos en los que el proceso aún no ha concluido por decisión que se pronuncie sobre la condena o absolución, e incluso en los que la celebración del juicio oral no ha tenido lugar, resulta prematura la invocación de lesiones que podrían ser examinadas ulteriormente en el curso del proceso: SSTC 76/2009, de 23 de marzo, y 78/2009, de 23 de marzo (en similares términos antes, la STC 73/2009, de 26 de abril). En las dos sentencias citadas (76/2009 y 78/2009) se ha reiterado que el marco natural en el que ha de intentarse la reparación del derecho constitucional vulnerado por la actuación del órgano jurisdiccional es el mismo proceso judicial previo, de tal modo que, en principio, sólo cuando éste haya finalizado por haber recaído una resolución firme y definitiva puede entenderse agotada la vía judicial y, consecuentemente, es posible acudir ante este Tribunal en demanda de amparo. 


\section{FUENTES DEL DERECHO}

La STC 49/2018, de 10 de mayo, del Pleno, resuelve un recurso de inconstitucionalidad interpuesto por el Parlamento de Cataluña respecto de diversos preceptos de la Ley Orgánica 8/2013, de 9 de diciembre, para la mejora de la calidad educativa. Según la representación de la región autónoma recurrente, la normativa vulneraría las competencias que el Estatuto de Autonomía de Cataluña reserva a la comunidad autónoma en materia de educación, universidades y lengua propia (arts. 2, 131, 153 y 172 del Estatuto de Autonomía). Se da la circunstancia de que uno de los preceptos de la norma recurrida (art. 6 bis), si bien guardaba al Estado solamente la posibilidad de realizar ciertas recomendaciones didácticas para configurar un marco común mínimo educativo, luego, determinaba que las distintas Administraciones educativas y los centros docentes en relación con la educación también podían «realizar recomendaciones de metodología didáctica para los centros docentes de su competencia». La representación de la comunidad autónoma no está de acuerdo con este régimen de coparticipación de distintas Administraciones de cara a la emisión de consejos y recomendaciones en materia de educación, que a la postre también — según ella - limitaría las propias posibilidades competenciales en materia educativa de la Generalitat de Cataluña. A su juicio, además, este tema (determinación de metodología didáctica) es una cuestión colateral del derecho fundamental a la educación del art. $27 \mathrm{CE}$, razón por la cual no se sujeta al principio de reserva de ley orgánica del art. $81 \mathrm{CE}$. El Tribunal reconoce que hay, en efecto, cuestiones colaterales que muchas veces pueden salirse del marco regulado por norma de rango orgánico y, en efecto, «hay normas básicas educativas que, en cuanto tales, pueden vincular a las Comunidades Autónomas, pero deben adoptarse sin rango orgánico por no desarrollar el artículo $27 \mathrm{CE}$ en el sentido del artículo $81 \mathrm{CE}$ ». Ahora bien, en otros casos, la realización de los fines de la enseñanza y el consecuente desarrollo del derecho a la educación (art. $27 \mathrm{CE}$ ) reclama a veces la máxima claridad posible en la definición de las tareas de las distintas Administraciones educativas, entre las cuales se encuentra igualmente la determinación por el Estado de ciertas recomendaciones didácticas mínimas, siendo así dable también su regulación por vía de norma de rango orgánico del art. 81.1 CE.

La STC 66/2018, de 21 de junio, del Pleno, resuelve un recurso de inconstitucionalidad interpuesto por el Gobierno de Canarias también contra distintos preceptos de la Ley Orgánica 8/2013, de 9 de diciembre, para la mejora de la calidad educativa. A juicio de la representación de la comunidad autónoma, se produce infracción de la reserva de ley orgánica y de ley ordinaria por cuanto se instaura un nuevo modelo de separación del alumnado por itinerarios en la ESO que, a pesar de su trascendencia, no está suficientemente 
regulado, posibilitando una reconducción a normas de rango reglamentario para la concreción posterior de cuestiones esenciales que repercuten en la configuración del derecho a la educación (lesión del art. 81.1 CE, reserva general de ley del art. 53.1 CE, y, en conexión, derecho a la educación del art. 27 CE). El Tribunal no admite esta hipótesis. Citando su STC 31/2018, de 10 de abril - que también contenía una queja en este sentido- indica que «la reserva de ley no excluye la posible colaboración normativa del reglamento, aunque condicionada a estrictas condiciones», debiendo quedar reducida esta posibilidad de corregulación «a los casos en los que, por exigencias prácticas, las regulaciones infralegales sean las idóneas para fijar aspectos de carácter secundario y auxiliares de la regulación legal del ejercicio de los derechos fundamentales». Tampoco a juicio del Tribunal puede olvidarse que la propia Ley Orgánica 2/2006, de 3 de mayo, de Educación, «atribuye al Gobierno, respecto a las etapas educativas de educación primaria, educación secundaria obligatoria y bachillerato, una amplia potestad reglamentaria en la determinación de contenidos comunes, estándares de aprendizaje evaluables y horario lectivo mínimo del bloque de asignaturas troncales, y en la determinación de los estándares de aprendizaje evaluables del bloque de asignaturas específicas». En definitiva, se desestima el recurso de inconstitucionalidad.

En materia de límites de los decretos leyes y de concurrencia del presupuesto habilitante de extraordinaria y urgente necesidad, cabe destacar la STC 61/2018, de 7 de julio (Pleno). El recurso de inconstitucionalidad se interpuso frente al Real Decreto Ley 5/2013, de 15 de marzo, de medidas para favorecer la continuidad de la vida laboral de los trabajadores de mayor edad y promover el envejecimiento activo. A juicio de los diputados recurrentes dicho real decreto ley carecía de razonamientos de extraordinaria y urgente necesidad para su aprobación. La norma, por ejemplo, por razones de economía, en su disposición final primera, procedía a limitar el acceso al subsidio por desempleo de mayores de 55 años en aquellos casos en los que dentro de la unidad familiar del peticionario hubiera otro tipo de rentas y estas sumasen el $75 \%$ del salario mínimo interprofesional (Alonso Gómez, 2018). Ahora bien, la norma solamente indicaba de forma aproximativa y vaga el análisis de su impacto económico y presupuestario, sin quedar clara la razón de la aprobación de dichas medidas por vía del 86.1 CE; tampoco quedaba acreditado en qué grado esta medida era necesaria en relación con la sostenibilidad del sistema de Seguridad Social. El Tribunal da la razón a los recurrentes, pues, a su criterio, en efecto, en el presente caso no había nada que indicara que la regulación introducida tratara de «dar respuesta a una situación de naturaleza excepcional» o constituyera «una necesidad urgente, hasta el punto de que su efectividad no pudiera demorarse durante el tiempo necesario para permitir su tramitación por el procedimiento legislativo ordinario». 
Interesa la STC 135/2018, de 13 de diciembre (Pleno), que resuelve la cuestión de inconstitucionalidad planteada por la Sala de lo Contencioso-Administrativo del Tribunal Supremo respecto del art. 367.1 de la LOPJ. Este precepto preveía que los jueces suspendidos temporalmente de servicio activo por falta disciplinaria, de cara al reingreso, debían solicitar "previa declaración de aptitud por el Consejo General del Poder Judicial, quien recabará los informes y practicará las actuaciones necesarias para su comprobación». El Tribunal critica el carácter poco determinado del precepto en cuestión. En efecto, a su juicio, "el término "aptitud" aparece desasido de cualquier ropaje jurídico que permita delimitarlo, produce una incertidumbre insuperable acerca de los aspectos a tomar en consideración para valorar la misma [...], no permite definir qué debe entenderse por aptitud y en consecuencia cuáles son los parámetros para valorar la idoneidad, suficiencia o capacidad de quien pretenda dicha declaración». El hecho de que no se den en el artículo mayores criterios para proceder al examen, tampoco de qué elementos se han de tener en cuenta para la evaluación de aptitud de cara al cese de la sanción de suspensión de funciones, de forma clara e indubitada, lleva a una lesión de las garantías de seguridad jurídica (art. 9.3 CE) y reserva de ley (arts. 117.2 y 122.1 CE), razones por las cuales procede a declarar la inconstitucionalidad y nulidad del precepto impugnado.

\section{ORGANIZACIÓN TERRITORIAL DEL ESTADO}

En su día, la STC 106/2014, de 24 de junio, ya resolvió un recurso de inconstitucionalidad contra la Ley del Parlamento de Cantabria 1/2013, de 15 de abril, por la que se regulaba la prohibición en el territorio de la comunidad autónoma de Cantabria de la fractura hidráulica como técnica de investigación y extracción de gas no convencional. Aquella norma tenía por objeto prohibir en todo el territorio de la comunidad autónoma de Cantabria el uso de la técnica denominada fractura hidráulica o fracking, utilizada para la investigación y extracción de gas de esquisto o no convencional, por medio de la inyección de agua con arena y aditivos químicos en las fracturas existentes en el sustrato rocoso que lo encierra. En aquel fallo ya el Tribunal Constitucional no entraba a analizar la norma en términos medioambientales, sino solamente en términos competenciales, determinando, sobre la aplicación de los arts. 149.1.13 y $25 \mathrm{CE}$ (competencia estatal en materia de actividad económica general y régimen minero y energético), que estas cuestiones entran dentro de las facultades regulatorias del Estado mediante la aprobación de la legislación básica; luego, a las comunidades autónomas les pueden corresponder las competencias de desarrollo normativo y ejecutivo, respetando las bases establecidas por el Estado (también así las SSTC 134/2014, de 22 de 
julio, y 208/2014, de 15 de diciembre) (Oehling de los Reyes, 2015). Pues bien, la STC 8/2018 (Pleno), de 25 de enero, vuelve sobre lo mismo, en este caso en relación con un recurso de inconstitucionalidad interpuesto por el presidente del Gobierno respecto a determinados preceptos de la Ley del Parlamento vasco 6/2015, de 30 de junio, de medidas adicionales de protección medioambiental para la extracción de hidrocarburos no convencionales y la fractura hidráulica. Aquí vuelve a afirmar, sobre la base de los arts. 149.1.13 y $25 \mathrm{CE}$, que la prohibición de manera absoluta e incondicionada de una técnica de investigación y explotación de hidrocarburos (el fracking) sobrepasa las posibilidades de la comunidad autónoma en materia de medio ambiente; ahora bien, no así aquella normativa autonómica que solamente vaya dirigida a establecer ciertos requisitos y cargas para el otorgamiento de autorizaciones y concesiones siempre que tales exigencias sean «razonables y proporcionadas al fin propuesto» y no «alteren el ordenamiento básico en materia de régimen minero y energético" (STC 106/2014, de 24 de junio). En este caso concreto, a juicio del Tribunal, la norma vasca objeto de recurso no podía ser considerada irrazonable ni desproporcionada en relación con el fin propuesto, puesto que la prohibición autonómica recurrida tiende a establecer límites respecto a autorizaciones de explotación que puedan tener efectos nocivos en acuíferos de la comunidad autónoma; es decir, tiende a proteger un recurso esencial del medio ambiente, el agua, lo cual requiere de un control adicional de cara a la previsión de sus efectos contaminantes. Por tanto, en lo que a esto respecta, el Tribunal Constitucional rechaza la objeción del Ejecutivo. En cambio, sí declara la inconstitucionalidad de la norma en relación con los límites que impone en los terrenos clasificados como suelo no urbanizable, por imprecisión de contenido, a saber, por falta de «determinación precisa de requisitos razonables y proporcionados al fin de protección medioambiental» (STC 73/2016, de 14 de abril); como también en la extensión de límites que la ley hacía en relación con yacimientos de metano en el mar, por cuanto vulnera la competencia sobre el subsuelo marino del Estado, que es al que corresponda otorgar las autorizaciones de exploración, permisos de investigación y concesiones de explotación en el mismo.

La STC 40/2018 (Pleno), de 26 de abril, versa sobre un recurso de inconstitucionalidad planteado por el Ejecutivo frente a la Ley Foral 14/2007, de 4 de abril, del patrimonio de Navarra, con resultado desestimatorio. El recurso tenía por objeto la impugnación de los preceptos de la norma que preveían la reversión a la Comunidad Foral de Navarra de los inmuebles vacantes en Navarra y de las cuentas, saldos y depósitos abandonados en entidades financieras situadas en la comunidad autónoma, a juicio del abogado del Estado esta regulación excede de las competencias autonómicas y la competencia exclusiva del Estado sobre legislación civil ex art. 149.1.8 CE. El Tribunal 
para la resolución de la duda de constitucionalidad parte de la validez de una norma preconstitucional, la Ley 1/1973, de 1 de marzo, por la que se aprueba la Compilación de Derecho civil foral de Navarra; también, con ello, de las Leyes de fueros de 1839 y de 1841, así como a la Ley de mostrencos de 9 de mayo de 1835. Para el Tribunal estas leyes anteconstitucionales ya regulaban los llamados abintestatos o, lo que es lo mismo, la sucesión intestada a favor de la comunidad foral, de ahí la legitimidad a su juicio del legislador autonómico para regular esta materia (art. 304.7 de la Ley 1/1973, de 1 de marzo). Luego, la STC 41/2018 (Pleno), de 26 de abril, en relación con un proceso de inconstitucionalidad frente a la Ley 5/2011, de 10 de marzo, del patrimonio de Aragón, que también preveía la atribución a dicha comunidad autónoma de las fincas cuyo dueño no fuese conocido, se resuelve igual, con resultado estimatorio para la comunidad autónoma, sobre la base de prerrogativas, derechos especiales o forales, preexistentes al texto constitucional, y también el derecho foral aragonés.

Cabe recordar aquí también ahora la STC 177/2016, de 20 de octubre, que resolvía el recurso de inconstitucionalidad interpuesto desde el Senado respecto a la Ley del Parlamento de Cataluña 28/2010, de 3 de agosto, que venía a prohibir expresamente, entre otras prácticas, las peleas de perros, de gallos, matar animales en espacios públicos, atracciones feriales giratorias con animales atados, y también las corridas de toros. En aquel caso, el Tribunal Constitucional ya determinó la inconstitucionalidad de la norma, también por su contradicción con la Ley 18/2013, de 12 de noviembre, para la regulación de la Tauromaquia como patrimonio cultural (Oehling de los Reyes, 2017), que determina expresamente en su art. 2 que «la Tauromaquia, en los términos definidos en el artículo 1, forma parte del patrimonio cultural digno de protección en todo el territorio nacional, de acuerdo con la normativa aplicable y los tratados internacionales sobre la materia». Pues bien, ahora, en la STC 134/2018 (Pleno), de 13 de diciembre, en relación con la Ley 9/2017, de 3 de agosto, de regulación de las corridas de toros y de protección de los animales en las Islas Baleares, hace lo propio. Es verdad que la norma en sí no prohibía las corridas de toros, pero establecía limitaciones - tales como la prohibición de la presencia de caballos durante las corridas de toros, prohibición del uso de utensilios que pudieran hacer daño al animal, etc.- - que privaban la fiesta de su sentido original, en clara contradicción también con la propia Ley 10/2015, de 26 de mayo, para la salvaguardia del Patrimonio Cultural Inmaterial, que establece como principio general de las actuaciones de los poderes públicos, de cara a la protección de las manifestaciones artísticas, velar para evitar las alteraciones cuantitativas y cualitativas de sus elementos propios y culturales (art. 3, letra h). En definitiva, sobre esa base, la doctrina sentada en la STC 177/2016, y, asimismo, el art.149.2 CE, que determina 
como competencia estatal la función de garante del acceso a la cultura (art. 44.4 y $5 \mathrm{CE}$ ), la preservación y enriquecimiento del patrimonio histórico, artístico y cultural español (art. $46 \mathrm{CE}$ ), el Tribunal determina la inconstitucionalidad de la norma.

\section{ORGANIZACIÓN DE LOS PODERES PÚBLICOS}

Interesa aquí citar en particular la STC 124/2018, de 14 de noviembre, del Pleno. Este fallo resuelve un conflicto entre órganos constitucionales del Estado interpuesto por la letrada de las Cortes Generales en contra del Gobierno, en relación con el no sometimiento del mismo a iniciativas de control del Congreso de los Diputados, más concretamente por la negativa a una comparecencia urgente del ministro de Defensa en funciones solicitada por la Comisión de Defensa para informar sobre los asuntos tratados y los acuerdos adoptados en la reunión de ministros de defensa de la OTAN, celebrada los días 10 y 11 de febrero de 2016 en Bruselas. Se daba la circunstancia de que el Ejecutivo, tras las elecciones de 20 de diciembre de 2015, desde el 21 de diciembre, estaba en funciones, de conformidad con el art. 101.2 CE, y, por esto, decidió no comparecer, sobre la base de que la Cámara no podía someter al Gobierno en funciones a iniciativas de control, tampoco ante la Comisión de Defensa, «en la medida en que no existe relación de confianza entre un Gobierno en funciones y el Congreso de los Diputados» (Oficio de 10 de marzo de 2016). A juicio del Gobierno, «la exigencia de responsabilidad política, ejercida por el Parlamento a través de los instrumentos de control a los que alude el título $\mathrm{V}$ de la $\mathrm{CE}$, solo es predicable respecto de un Gobierno que goce de la confianza de la Cámara»; dado que la confianza de la Cámara otorgada en la anterior legislatura —a su juicio- había periclitado, no procedía someterle a control, por cuanto su actividad se reducía a la mera gestión de despacho ordinario de asuntos públicos (art. 21 de la Ley 50/1997, de 27 de noviembre, del Gobierno), entendiendo esta actividad como no fiscalizable. El problema, por tanto, con la incomparecencia era «no sólo que con ello no se sometió pasivamente al control que ejercían los parlamentarios, sino que, más allá, ejerció una oposición activa a dicho ejercicio» (Delgado Ramos, 2018a). En el escrito de interposición del conflicto por parte del servicio de letrados de las Cortes se alega que esta negativa lesiona los principios de Estado democrático, sujeción de los poderes públicos a la $\mathrm{CE}$ y al ordenamiento jurídico, principios de seguridad jurídica y de responsabilidad e interdicción de la arbitrariedad de los poderes públicos, el derecho de participación política, la función de control parlamentario al Gobierno, el principio de responsabilidad política del Ejecutivo y la facultad de los miembros del Parlamento de formular preguntas con respuesta oral tanto en el Pleno como en las distintas 
comisiones (arts. 1, 9, 23, 66.2, 108, 109, 110 y 111 CE). Naturalmente, el Tribunal Constitucional da la razón a los recurrentes.

La función de control — dice el Tribunal con claridad meridiana— que corresponde a las Cortes Generales está implícita en su carácter representativo y en la forma de gobierno parlamentario que establece el art 1.3 CE, no pudiendo negarse a las Cámaras todo ejercicio de la función de control, ya que con ello se afectaría al equilibrio de poderes previsto en nuestra Constitución. A ello ha de añadirse que la función de control corresponde al Congreso de los Diputados y al Senado, conforme al artículo 66.2 CE, aunque entre esta Cámara y el Gobierno no exista dicha relación de confianza, lo que significa que, conforme al referido precepto, no sea necesaria la existencia de dicha relación fiduciaria para el ejercicio de la función de control. Resulta también relevante que no todos los instrumentos de control tienen como finalidad la ruptura de la relación de confianza, porque ello supone que, como antes se explicó, no es necesario que dicha relación exista para el ejercicio de la función de control. Como hemos afirmado con anterioridad, el hecho de que el Gobierno esté en funciones no impide la función de control de las Cámaras, ya que en la medida en que el Gobierno sigue desarrollando actividad, esta no puede quedar exenta del control de las Cortes Generales conforme a los artículos 1 y $66 \mathrm{CE}^{8}$.

En definitiva, "si hay Gobierno, aunque sea en prorrogatio, debe haber control parlamentario al mismo, porque no puede haber un Gobierno sin control, sean cuales sean sus competencias» (Delgado Ramos, 2018b).

\section{DERECHOS FUNDAMENTALES}

En materia de igualdad del art. 14 CE, cabe citar las SSTC 111/2018 (Pleno), de 17 de octubre, y 138/2018 (Sala Primera), de 17 de diciembre. Los recursos de amparo tienen origen en sendas denegaciones de la Dirección provincial del INSS de Madrid a dos peticiones de padres interesando la ampliación y equiparación de la prestación de paternidad con la prestación por maternidad, bien en lo que se refiere a las condiciones de disfrute como a su duración (dieciséis semanas, en vez de trece días, que es lo que se determina para el padre en el antiguo art. 48 bis del texto refundido de la Ley del estatuto de los trabajadores aprobado por Real Decreto Legislativo 1/1995, de 24 de marzo [hoy materia regulada en el Real Decreto Legislativo 2/2015, de 23 de octubre, por el que se aprueba el texto refundido de la Ley del Estatuto de los Trabajadores]). El Tribunal Constitucional desestima el amparo, también por el mismo hecho físico diferenciador de llevar el embarazo y el parto, que

8 Sobre ello, Herreros López (2019). 
requiere - por eso mismo- de un mayor descanso en comparación con el padre, que lógicamente no tiene que sobrellevarlo. El Tribunal establece lo siguiente:

Siendo diferentes las situaciones que se traen a comparación, no puede reputarse como lesiva del derecho a la igualdad ante la ley (art. $14 \mathrm{CE}$ ) la diferente duración de los permisos por maternidad o paternidad y de las correspondientes prestaciones de la seguridad social que establece la legislación aplicada en las resoluciones administrativas y judiciales que se impugnan en amparo. La atribución del permiso por maternidad, con la correlativa prestación de la seguridad social, a la mujer trabajadora, con una duración superior a la que se reconoce al padre, no es discriminatoria para el varón. Este Tribunal ya ha tenido ocasión de señalar que la maternidad, el embarazo y el parto son realidades biológicas diferenciadas de obligatoria protección, derivada directamente del artículo 39.2 CE, que se refiere a la protección integral de las madres. Por tanto las ventajas que se determinen para la mujer no pueden considerarse discriminatorias para el hombre (SSTC 109/1993, de 25 de marzo, y 75/2011, de 17 de mayo).

En materia de libertad personal (arts. $17 \mathrm{CE}$ ) interesa indicar la STC 21/2018 (Sala Primera), de 5 de marzo. Ya en la STC 13/2017, de 30 de enero, pudimos ver cómo la Ley Orgánica 5/2015, de 27 de abril, transponía al ordenamiento jurídico la Directiva 2010/64/UE, de 20 de octubre, relativa al Derecho a Interpretación y a Traducción en los Procesos Penales, y la Directiva 2012/13/UE, de 22 de mayo de 2012, relativa al Derecho a la Información en los Procesos Penales, así como las nuevas garantías en materia del derecho a la información en los procesos penales que se han introducido en el art. 520 de la Ley de Enjuiciamiento Criminal (Oehling de los Reyes, 2017). Pues bien, este fallo versa también sobre esta cuestión, a saber, una detención preventiva en la que la instrucción, previa solicitud, no permitió el acceso de la parte al atestado, en contradicción con el art. 520.2.d de la Ley Rituaria. Por lo visto, a la hora de informar sobre las razones de la detención, los agentes de policía fueron parcos en datos, limitándose a proporcionarle información verbal muy general sobre que se había producido una pelea callejera y sobre el lugar de la agresión. Así las cosas, la defensa interpuso recurso de habeas corpus que fue inadmitido a limine. El Tribunal Constitucional otorga el amparo por dos razones: por un lado, por la resolución anticipada e indebida de la solicitud de habeas corpus, que hubiera posibilitado el planteamiento y subsanación de las posibles irregularidades de la detención; por otro lado, por la falta del cumplimiento del trámite de información en dependencias policiales, por cuanto hubiera sido necesario transmitirle mayores datos sobre la acusación (coincidencia de edad con respecto al resto de detenidos, efectos del delito incautados, etc.), es decir, por falta de información necesaria que podía 
interesar a la parte para cuestionar la suficiencia o consistencia de las razones reales que justificaron la detención. En definitiva, se otorga el amparo por lesión del derecho a la libertad personal (art. 17.1 y $3 \mathrm{CE}$ ).

En materia de libertad personal interesa también citar los AATC 53 y 54/2018, de 22 de mayo, y 82/2018, 17 de julio, todos del Pleno. Es sabido que el art. 56.1 de la LOTC establece, como regla general, que «la interposición de un recurso de amparo no suspenderá los efectos del acto o sentencia impugnados», si bien el apartado segundo del mismo artículo posibilita «la suspensión del acto o sentencia impugnados cuando su ejecución produzca un perjuicio al recurrente que pudiera hacer perder su finalidad al amparo, siempre y cuando la suspensión no ocasione perturbación grave a un interés constitucionalmente protegido, ni a los derechos fundamentales o libertades de otra persona». Pues bien, sobre la base de este precepto, algunos de los golpistas de octubre de 2017 en prisión provisional solicitaban al Tribunal Constitucional la suspensión del auto dictado por el magistrado instructor de la causa que acordaba la prisión provisional comunicada y sin fianza de los recurrentes. Los arts. 503 y siguientes de la Ley de Enjuiciamiento Criminal son claros en este sentido, determinando el sentido finalista del mantenimiento de un sujeto en prisión provisional, a saber, grosso modo, asegurar el proceso y evitar su huida, evitar que este pueda ocultar, destruir o manipular pruebas, y, asimismo, evitar que el delincuente pueda volver a delinquir. En cambio, el conjunto de razones que los encartados alegan para obtener dicha medida especialísima no rebaten ninguna de las causas que figuran en la plantilla del art. 503, sino que simplemente refieren circunstancias personales - lejanía del hogar y circunstancias familiares-, no muy distintas de las que pueda tener cualquier otro preso en situación de provisional. El Tribunal Constitucional deniega la petición de suspensión de las resoluciones de la jurisdicción ordinaria y las restantes medidas cautelares solicitadas. Recordando su doctrina anterior, afirma que la posibilidad de acordar la suspensión de decisiones judiciales en que se acuerdan medidas cautelares privativas de libertad —en este caso la prisión provisional, que ciertamente supone una afección del derecho a la libertad personal y puede producir perjuicios irreparables- puede suponer un otorgamiento anticipado del amparo, razón por la cual «ha rechazado la posibilidad de su suspensión en el procedimiento de amparo» (así, por ejemplo, AATC 4/2006, de 12 de febrero, 41/2007, de 16 de enero, 219/2008, de 14 de julio, 94/2010, de 19 de junio, y 173/2017, de 18 de diciembre). En cualquier caso, hay que recordar también que, poco después del encarcelamiento, estos delincuentes han sido trasladados por el Ministerio del Interior a prisiones muy cercanas a su domicilio.

En relación con el derecho al honor, a la intimidad personal y familiar y a la propia imagen (art. 18.1), hay que destacar la STC 58/2018 (Sala Pri- 
mera), de 4 de junio. En los años ochenta, se produjo el desmantelamiento de una red de tráfico de estupefacientes, de lo cual se hizo noticia el rotativo El País dando ciertos nombres de detenidos y afectados. Veinte años más tarde, El País estableció un servicio gratuito de acceso a su hemeroteca digital, contenida en el sitio web www.elpais.com, por medio del cual, introduciendo los nombres y apellidos de los protagonistas de aquella noticia — también por medio del proveedor de servicios de intermediación de búsqueda en Internet (www.google.es) —, aparecía como primer resultado aquella noticia, y un extracto de la misma. Así las cosas, los interesados solicitaron de El País que cesara en el tratamiento de sus datos personales o, subsidiariamente, que sustituyera en la noticia los nombres y apellidos por sus iniciales, u otras medidas de cara a proteger su intimidad. En cambio, el diario, basándose en su derecho fundamental a la libertad de información y en la imposibilidad de evitar la indexación por los buscadores, no accedió a la solicitud. Lo cierto es que la tendencia en materia de "derecho al olvido», desde la STJUE de 13 de mayo de 2014, asunto Google Spain, S.L. y AEPD, Mario Costeja González, es bastante garantista, reconociéndolo incluso como derecho subjetivo (art. 94 de la Ley Orgánica 3/2018, de 5 de diciembre, de Protección de Datos Personales y garantía de los derechos digitales, y art. 17 del Reglamento [UE] 2016/679, de 27 de abril de 2016, relativo a la protección de las personas físicas en lo que respecta al tratamiento de datos personales). Así las cosas, los afectados interpusieron demanda de juicio ordinario contra la editorial, por vulneración del derecho al honor, a la intimidad y a la protección de datos de carácter personal (art. 18.1 y 4 CE). En primera instancia se estimó íntegramente la demanda, condenando a la editorial al abono de una indemnización, al cese inmediato en la difusión de la noticia y a la implantación de las medidas tecnológicas solicitadas en la demanda, luego fue ratificada por sentencia de la Audiencia Provincial de Barcelona. En cambio, en casación, el Tribunal Supremo entendió caducada la acción, reformulando las medidas de reparación acordadas en instancia. Contra esta última resolución, dictada por la Sala de lo Civil del Tribunal Supremo, la parte interpuso recurso de amparo. El Tribunal Constitucional otorga el amparo.

La prohibición de indexar los datos personales — dice LA Sala Primera-, en concreto los nombres y los apellidos de las personas recurrentes, para su uso por el motor de búsqueda interno de El País debe ser considerada una medida limitativa de la libertad de información idónea, necesaria y proporcionada al fin de evitar una difusión de la noticia lesiva de los derechos invocados. La medida requerida es necesaria porque su adopción, y solo ella, limitará la búsqueda y localización de la noticia en la hemeroteca digital sobre la base de datos personales inequívocamente identificativos de las personas recurrentes. A este respecto debe tenerse en cuenta 
que los motores de búsqueda internos de los sitios web cumplen la función de permitir el hallazgo y la divulgación de la noticia, y que esa función queda garantizada aunque se suprima la posibilidad de efectuar la búsqueda acudiendo al nombre y apellidos de las personas en cuestión, que no tienen relevancia pública alguna.

\section{Bibliografía}

Alonso García, M. N. (2018). Hacia la «parlamentarización» de los PGE: Visión crítica de la STC 34/2018, de 12 de abril. Revista Jurídica de la Universidad de León, 5, 129-135. Disponible en: https://bit.ly/2Wnc29n.

Alonso Gómez, R. (2018). El TC elimina el requisito de carecer de rentas familiares para acceder al subsidio de mayores de 55 años. Legaltoday. Disponible en: https://bit.ly/2PrxOYf.

Beltrán de Felipe, M. y Sarmiento Ramírez-Escudero, D. (2017). Un Tribunal para la Constitución. Madrid: Colegio de Registradores de la Propiedad, Mercantiles y Bienes Muebles de España.

Consejo de Transparencia y Buen Gobierno (2017). Informe de evaluación de los órganos constitucionales y reguladores. Madrid: Consejo de Transparencia y Buen Gobierno. Disponible en: https://bit.ly/2Nnz5ge.

De Miguel Bárcena, J. (2018). El proceso soberanista ante el Tribunal Constitucional. Revista Española de Derecho Constitucional, 113, 347-352. Disponible en: https://doi.org/10.18042/cepc/redc.113.05.

Delgado Ramos, D. (2018a). Problemas actuales de Derecho Parlamentario. Cizur Menor (Navarra): Thomson Reuters Aranzadi.

- (2018b). El control parlamentario del Gobierno en funciones en España: La experiencia de la XI Legislatura (2016). Estudios Constitucionales, 16 (2), 183220. Disponible en: https://bit.ly/32YIMbu.

- (2019). El veto presupuestario del Gobierno. Revista de Estudios Políticos, 183, 67-99. Disponible en: https://doi.org/10.18042/cepc/rep.183.03.

Duque Villanueva, J. C., Ortega Carballo, C., Losada González, H. y De la Quadra Salcedo Janini, T. (2018a). Doctrina del Tribunal Constitucional durante el primer cuatrimestre de 2018. Revista Española de Derecho Constitucional, 113, 229-276. Disponible en: https://doi.org/10.18042/cepc/redc.113.08.

- (2018b). Doctrina del Tribunal Constitucional durante el segundo cuatrimestre de 2018. Revista Española de Derecho Constitucional, 114, 191-233. Disponible en: https://doi.org/10.18042/cepc/redc.114.07.

- (2019). Doctrina del Tribunal Constitucional durante el tercer cuatrimestre de 2018. Revista Española de Derecho Constitucional, 115, 253-301. Disponible en: https://doi.org/10.18042/cepc/redc.115.09.

Elvira Perales, A. y Espinosa Díaz, A. (coords.) (2018a). Actividad del Tribunal Constitucional: relación de sentencias dictadas durante el primer cuatrimestre de 
2018. Revista Española de Derecho Constitucional, 113, 199-227. Disponible en: https://doi.org/10.18042/cepc/redc.113.07.

- (coords.) (2018b). Actividad del Tribunal Constitucional: relación de sentencias dictadas durante el segundo cuatrimestre de 2018. Revista Española de Derecho Constitucional, 114, 165-190. Disponible en https://doi.org/10.18042/ cepc/redc. 114.06 .

- (coords.) (2019). Actividad del Tribunal Constitucional: relación de sentencias dictadas durante el tercer cuatrimestre de 2018. Revista Española de Derecho Constitucional, 115. Disponible en: https://doi.org/10.18042/cepc/ redc. 115.08 .

Herreros López, J. M. (2019). El control parlamentario del Gobierno en funciones. Comentario de la STC 124/2018, de 14 de noviembre. Actualidad administrativa, 6, 2019.

Oehling de los Reyes, A. (2015). Crónica de la jurisprudencia constitucional española en el año 2014. Anuario Iberoamericano de Justicia Constitucional, 19, 548549. Disponible en: http//:dx.doi.org/10.18042/cepc/aijc.19.18.

- (2017). Crónica de la jurisprudencia constitucional española en el año 2016. Anuario Iberoamericano de Justicia Constitucional, 21, 258-259. Disponible en: https://doi.org/10.18042/cepc/aijc.21.10.

Requejo Pagés, J. L. (2018). Un Tribunal para la Constitución. Revista Española de Derecho Constitucional, 114, 347-352. Disponible en: https://bit.ly/2pVEkf7.

Rubio Llorente, F. (2012). La forma del poder. Estudios sobre la Constitución (vol. 3). Madrid: Centro de Estudios Políticos y Constitucionales.

Triana Reyes, B. (2018). ¿Qué hacer antes de ir al amparo? Respuesta de la Sección Primera del Tribunal Constitucional (ATC 65/2018, de 18 de junio). Diario La Ley, 9262.

Tribunal Constitucional (2018). Tribunal Constitucional. Memoria 2018. Madrid: Boletín Oficial del Estado. Disponible en: https://bit.ly/34qGG4D. 